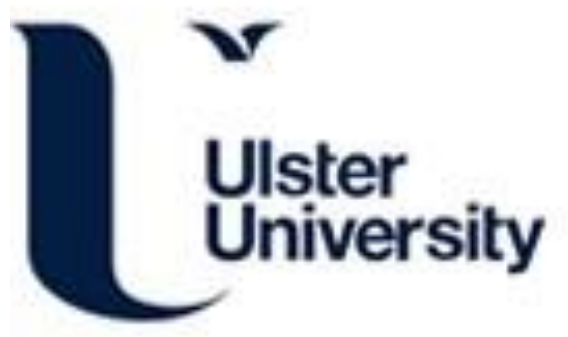

\title{
Did advice on the prescription of Sodium Valproate reduce prescriptions to women? An observational study in three European countries between 2007 and 2016
}

Charlton, R., Damase-Michel, C., Hurault-Delarue, C., Gini, R., Loane, M., Pierini, A., Puccini, A., Neville, A., Snowball, J., \& Morris, J. K. (2019). Did advice on the prescription of Sodium Valproate reduce prescriptions to women? An observational study in three European countries between 2007 and 2016. Pharmacoepidemiology and Drug Safety, 28(11), 1519-1528. https://doi.org/10.1002/pds.4881

Link to publication record in Ulster University Research Portal

Published in:

Pharmacoepidemiology and Drug Safety

Publication Status:

Published (in print/issue): 01/11/2019

DOI:

10.1002/pds.4881

\section{Document Version}

Author Accepted version

\section{General rights}

Copyright for the publications made accessible via Ulster University's Research Portal is retained by the author(s) and / or other copyright owners and it is a condition of accessing these publications that users recognise and abide by the legal requirements associated with these rights.

\section{Take down policy}

The Research Portal is Ulster University's institutional repository that provides access to Ulster's research outputs. Every effort has been made to ensure that content in the Research Portal does not infringe any person's rights, or applicable UK laws. If you discover content in the Research Portal that you believe breaches copyright or violates any law, please contact pure-support@ulster.ac.uk. 


\section{Did advice on the prescription of Sodium Valproate reduce prescriptions to women ?}

\section{An observational study in three European countries between 2007 and 2016}

Rachel Charlton ${ }^{1}$, Christine Damase-Michel ${ }^{2}$, Caroline Hurault-Delarue ${ }^{2}$, Rosa Gini ${ }^{3}$, Maria Loane ${ }^{4}$, Anna Pierini ${ }^{5}$, Aurora Puccini ${ }^{6}$, Amanda Neville ${ }^{7}$, Julia Snowball ${ }^{1}$, Joan K Morris ${ }^{8}$, on behalf of the EUROmediSAFE consortium

1. Department of Pharmacy \& Pharmacology, University of Bath, Bath, UK.

Rachel Charlton, Research Fellow

Julia Snowball, Database Manager/Research Fellow

2. Pharmacologie Faculté de Médecine, Université Toulouse III, CHU Toulouse, INSERM UMR1027, France.

Christine Damase-Michel, Associate Professor

Caroline Hurault-Delarue, Research Fellow

3. Agenzia regionale di sanità della Toscana, Italy

Rosa Gini, Dr

4. Institute of Nursing \& Health Research, Ulster University, Co Antrim, Northern Ireland.

Maria Loane, Reader in Public Health

5. Institute of Clinical Physiology - National Research Council (IFC-CNR)/Fondazione Toscana

"Gabriele Monasterio", Pisa, Italy

Anna Pierini, Researcher

6. Drug Policy Service, Emilia Romagna Region Health Authority, Bologna, Italy

Aurora Puccini, Dr

7. IMER (Emilia Romagna Registry of Birth Defects), Centre for Clinical and Epidemiological Research, University of Ferrara and Azienda Ospedaliero-Universitaria di Ferrara, Ferrara, Italy

Amanda J Neville, Research Fellow and Registry Leader

8. Centre for Environmental and Preventive Medicine, Queen Mary University of London, UK.

Joan Morris, Professor of Medical Statistics

Corresponding author: Joan Morris (j.k.morris@qmul.ac.uk)

Key words: Antiepileptic medications, Sodium valproate, Epidemiology, Healthcare databases 


\section{ABSTRACT}

Objectives : In November 2014 the CMDh (a regulatory body representing EU Member States) advised doctors not to prescribe sodium valproate for epilepsy or bipolar disorder in pregnant women, in women who can become pregnant or in girls unless other treatments are ineffective or not tolerated. This study aimed to determine if there is any evidence that this warning led to changes in prescription patterns of sodium valproate and other anti-epileptic drugs (AEDs) in women of childbearing age.

Design and setting : Cohort of 5.4 million women aged between 10 and 50 years identified in electronic health care data from United Kingdom, France, and Italy (2007-2016).

Main Outcome Measures : Anti-epileptic drug (AED) prescriptions.

Results: The prevalence of women receiving AED prescriptions in 2016 varied from 12.2 per 1000 to 29 per 1000 in the four regions. The incidence of prescribing any AED (excluding clonazepam, gabapentin and pregabalin - medications not commonly prescribed for epilepsy) fell in all regions each year on average by $7.5 \%$ (95\% $\mathrm{Cl}: 7.0 \%$ to $8.0 \%$ ) (Emilia Romagna) , $9.6 \%$ (8.3\% to $11.0 \%$ ) (France ) , 7.1\% (6.7\% to $7.6 \%$ ) (Tuscany) and $0.4 \%$ (0.2\% to $1.0 \%$ ) (UK). The relative odds of prescribing sodium valproate rather than any other AED (excluding clonazepam, gabapentin and pregabalin) decreased more from 2014 to 2016 compared to 2007 to 2013 in France (OR= 0.77 ( $95 \% \mathrm{Cl}: 0.60$ to 0.98$))$, Tuscany (0.81 (0.76 to 0.86$))$, Emilia Romagna (0.83 (0.76 to 0.90$)$ ) and the UK (0.92 (0.80 to 1.06; not statistically significant).

Conclusions : There is evidence that the CMDh warning in 2014 did lead to changes in prescription patterns of sodium valproate in women of childbearing age. There were considerable differences in prescribing practice amongst regions of Europe. 


\section{Section 1: What is already known on this topic}

- Sodium valproate exposure during the first trimester is associated with the occurrence of congenital anomalies and also neurodevelopmental delays

- The European Medicines Agency sent warnings to health care professionals to limit sodium valproate prescriptions to women for whom other alternatives are not possible and to inform patients of the risks in November 2014.

- It is unknown if these warnings have any effect on prescribing patterns in Europe

\section{Section 2: What this study adds}

- Prescription rates for sodium valproate compared to other anti-epileptic medications did fall after warnings were sent to health care professionals in 2014 


\section{INTRODUCTION}

Antiepileptic drugs (AEDs) are a diverse class of medicines that are prescribed for an increasing number of indications including epilepsy, bipolar disorder, migraine prophylaxis and neuropathic pain.[1-3] AEDs are commonly prescribed to women of childbearing age[4-9] and the prevalence of prescribing varies by geographic location $[9,10]$. The chronic and serious nature of some of the indications for which they are prescribed means that it is not always possible for women to discontinue their treatment in advance of and during pregnancy.[11-13] For some time there has been evidence that certain AEDs, when taken by women during their pregnancy, are associated with a two- to three-fold increase in risk of major congenital malformations in the offspring.[14-17] The risk varies by $A E D$, with sodium valproate often reported as having the highest risk[14] and lamotrigine and levetiracetam the lowest risk,[17] although for many of the other newer AEDs the number of exposures during pregnancy available for study is low. In recent years there has been a growing body of evidence of negative neurodevelopmental outcomes in children exposed to sodium valproate in-utero $[14,18-23]$.

In October 2013, the Medicines and Healthcare Regulatory Authority (MHRA) issued a referral into the use of sodium valproate in girls and women of childbearing potential. Following completion of the review by the Pharmacovigilance Risk Assessment Committee (PRAC) in the European Medicines Agency (EMA), the CMDh (a regulatory body representing EU Member States) strengthened warnings on the use of sodium valproate in women and girls due to the risk of malformations and developmental problems in babies exposed to sodium valproate in the womb. The warnings aim to ensure that patients are aware of the risks and that they take sodium valproate only when clearly necessary. The CMDh review resulted in a personal letter being sent to all healthcare professionals in all European countries in December 2014 informing them of the changes in the recommendations for valproate prescribing.

This study, capturing data from three European countries, aimed to determine if there is any evidence that warnings about the harm of sodium valproate to the fetus have led to changes in prescription patterns of sodium valproate and other AEDs in women of childbearing potential.

\section{METHODS}

Electronic healthcare databases from within four regions/countries contributed data to the study: the United Kingdom (UK-wide Clinical Practice Research Datalink (CPRD)), France (Echantillon 
Generaliste des Beneficiaires (EGB)): French Health Insurance System and Hospital Medical Information Systems (PMSI)), Emilia Romagna in Italy (Certificate of Delivery Assistance (CeDAP) and Emilia Romagna Prescription Database (ERPD)) and Tuscany in Italy (CeDAP, Hospital Discharges Registry and Tuscany Prescription Database (TPD)). An overview of the databases can be found in Table 1 and has been reported elsewhere.[24] Ethical and data access approvals were obtained for each database from the relevant governance infrastructures. The protocol was registered in the ENCePP PAS register (EUPAS21171).

Study population

A common protocol was used to extract data from all databases. The study period ran from 1 January 2007 until 31 December 2016. The source population consisted of all females in each database who were aged between 10 and 50 years at some point during the study period. Eligible females were required to have contributed a minimum of 365 days to the database.

\section{Exposure}

The exposures of interest were AEDs with an anatomical therapeutic chemical (ATC) code starting N03A and also clobazam (ATC N05BA09) which is licensed for epilepsy in the countries under study. Sodium valproate included both prescriptions for valproic acid and for valpromide. All AED prescriptions that were issued in the United Kingdom or dispensed in France and Italy to any female during her time in the study cohort were identified. In all four regions there was a large proportion of women with only a single AED prescription during the entire time they were in the study ( $38 \%$ in France, $31 \%$ in Emilia Romagna, 28\% in Tuscany and $22 \%$ in the United Kingdom). Around $75 \%$ of these women were prescribed gabapentin, pregabalin or clonazepam in France, the UK and Emilia Romagna (54\% in Tuscany). These three medications are often prescribed for neuropathic pain rather than epilepsy. Given the fact that AEDs are mostly associated with chronic treatment, irrespective of indication, it was decided that only females issued/dispensed more than 1 prescription for an AED during their time in the study cohort were defined as exposed. Sensitivity analysis including all women were performed.

A cohort of first-ever AED users was identified within the AED exposed cohort. 'First-ever users' were defined as those who received an AED prescription during the study period who had been in the database for $>365$ days prior to the date of their first AED prescription without any other AED prescribing during this time. 
For each female receiving an AED attempts were made to determine the indication for the AED prescribing. In all databases, this involved the creation of a unique database specific algorithm to utilise all available information which included some or all of the following: medical diagnoses, hospital discharge data, special reimbursement status or exemption codes, information on the type of prescriber, the specific name of the medicine and co-prescribing of other medicines such as psychotropic drugs. In Italy a modified version of the algorithm developed by Naldi et al was used[25], because the original algorithm did not attempt to determine prescribing for migraines or pain. The level of detail available varied between databases with the main aim being to distinguish between prescribing for epilepsy and prescribing for psychiatric conditions (such as bipolar disorder or anxiety) or pain (neuropathic pain or migraine).

\section{Patient and Public Involvement}

This research was done without patient involvement. Patients were not invited to comment on the study design and were not consulted to develop patient relevant outcomes or interpret the results. Patients were not invited to contribute to the writing or editing of this document for readability or accuracy.

\section{ANALYSIS}

The analyses were carried out separately for each database at the host institution and shell tables of aggregated results were then provided to the lead institution to be compiled. The prevalence of AED prescribing in females of childbearing age was calculated per 1000 female population with $95 \%$ confidence intervals $\left(\mathrm{Cl}_{95}\right)$ for 2016 using the Poisson distribution. The ten most common AEDs in 2016 were identified according to the prevalence in each region, with each region having the same weight (despite the differences in population sizes).

The annual change in incidence of AED prescribing in first-ever users was analysed using Poisson regression separately for each region. To determine if there was a change in the odds of prescribing sodium valproate rather than another AED from 2014 onwards an interrupted time series logistic regression model was fitted using segmented regression assuming that the change will be a gradual change in the gradient of the trend starting in 2014. This means that two straight lines are fitted: one from 2007 to 2014 and one from 2014 to 2016. A sensitivity analysis was performed including women who had only one AED prescription during the study period. The incidence of AED prescribing was also stratified by age at first prescription in the categories: $<20$ years old, $20-29$ 
years old, 30-39 years old and 40+ years old. For France the incidence of AED prescribing was also stratified by indication.

There was considerable missing data on the indication for AED prescribing. This variable was only analysed for France wen there was sufficient information available and the "other/unknown" outcome was identified on the table. OTHER COMMENTS ON MISSING DATA RACHEL ???

All analyses were performed using STATA 14.

\section{RESULTS}

Data were available from the four regions on a total of 5.4 million women from 2007-2016. The number of females captured in the databases in each region differed in size from the UK with 2.4 million women, Emilia Romagna with 1.6 million, Tuscany with 1.3 million and France with 190,000 women.

\section{Prevalence of women receiving AED prescriptions in 2016}

Table 2 shows that the prevalence of women being prescribed AEDs in 2016 varied considerably both between and within countries with the prevalence being lowest in Emilia Romagna at 12.2 (95\%Cl: 12.0-12.4) per 1000, higher in Tuscany and France (17.7 (17.5-18.0) and 19.1 (18.3-19.8) per 1000 respectively) and highest in the UK at $29.0(28.6$ - 29.3) per 1000. The women in Italy had a mean age two years older than those in France and the UK, but those being prescribed AEDs had similar ages in all the databases.

Table 2 also shows the prevalence of the ten most common medications in 2016. In contrast to the other regions 10.4 women per 1000 in the UK were prescribed gabapentin and 8.4 per 1000 were prescribed pregabalin - under 3 per 1000 women were prescribed either of these medications in the other regions apart from in France where 6.3 per 1000 women were prescribed pregabalin. Excluding prescriptions for gabapentin and pregabalin, valproate was the most frequently prescribed AED medication in all regions except for in the UK, where lamotrigine was more frequently prescribed, with the prevalence of valproate prescriptions varying from 6.6 per 1000 in Tuscany down to 2.7 per 1000 in the UK.

Incidence of AED prescribing from $2007-2016$ 
Figure 1a shows the changes in prescribing of AEDs to women who were first-time users for the ten years from 2007. The trends appear very different in the four regions, with large increases observed in the UK contrasting with large decreases in France. However, only a very small number of specific AEDs were responsible for these trends. When prescriptions of clonazepam, gabapentin and pregabalin were excluded, the trends were significantly decreasing in all regions by $9.6 \%(95 \% \mathrm{Cl}$ : 8.3\%-11.0\%) per year (France), 7.5\% (7.0\%-8.0\%) (Emilia Romagna), 7.1\% (6.7\%-7.6\%) (Tuscany) and $0.4 \%(0.2 \%-1.0 \%)$ (UK) (Figure 1b). The incidence of prescribing clonazepam, gabapentin and pregabalin in addition to the other eight most common AED medications according to year is given in Appendix 1 (Table A1 and Figure A1).

\section{Incidence of sodium valproate prescribing}

Figure 2 shows that the incidence of prescribing sodium valproate has fallen in all regions (2a) and that this fall is greater than the fall in other AEDs in France and the UK (2b) for the whole study period and for Emilia Romagna and Tuscany for the period from 2014. Table 3 shows that the odds of prescribing sodium valproate compared to any other AED (excluding clonazepam, gabapentin and pregabalin) decreased significantly from 2014 to 2016 and that this decrease was significantly greater from 2014 to 2016 than the annual changes from 2007 to 2016 in France and Italy - in the UK there had been a greater decrease in 2014 to 2016, but it was not statistically significant. Extremely similar estimates were obtained in the sensitivity analysis which included women with only a single AED prescription in the study period, resulting in the same degrees of statistical significance for France and Italy and the decrease in the UK being greater but not statistically significant $(\mathrm{P}=0.09)$.

\section{Incidence of prescribing sodium valproate according to age}

Figure 3 shows that the incidence of prescribing sodium valproate is highest in the oldest age groups (>40 years and $30-39$ years) and that it is in these age groups that the incidence is decreasing the greatest. A figure illustrating the incidence of prescribing the eleven most common AED medications according to age is given in Appendix 1 (Figure A2).

\section{Incidence of AED prescribing according to indication}

In all regions/countries apart from France there was a large proportion of females for which the indication could not be confidently assumed : $56 \%$ in Tuscany, $37 \%$ in Emilia Romagna and $28 \%$ in the UK compared with $11 \%$ in France. Hence only the incidence of AED prescribing according to indication is given for France and the algorithm used is given in Appendix A. Table 4 shows that for 
all AEDs $31 \%$ of prescriptions were for epilepsy and $40 \%$ for neuropathic pain, with some individual AED prescriptions being more likely to be for epilepsy (topiramate, carbamazepine, lamotrigine, levetiracetam, clobazam and oxcarbazepine) and valproate was more likely to be for bipolar disorders. The unknown indications were mainly for clonazepam prescriptions. Figure 4 shows that the incidence of valproate prescriptions is much greater for bipolar disorders than for epilepsy, apart from for women under 20 years of age. The incidence has decreased for both, with particularly large decreases for bipolar disorder following the warnings about sodium valproate in December 2014.

\section{DISCUSSION}

\section{Study Findings}

This study analysed data from two regions in Italy, from France and the United Kingdom on 5.4 million women aged 10-50 years between 1 January 2007 and 31 December 2016. In 2016 the United Kingdom had a much higher prevalence of AED prescribing than the other three regions (29 per 1000 compared to 19.1, 17.7 and 12.2 respectively for France, Tuscany and Emilia Romagna). However, two drugs (pregabalin and gabapentin) were taken by over $60 \%$ of AED exposed women in the UK and when these two drugs were excluded the prevalence in the UK was 12.8 per 1000, more consistent with the other regions. In 2016 valproate was the most frequently prescribed AED in Italy, the second most frequent in France after pregabalin and the fourth in the United Kingdom after gabapentin, pregabalin and lamotrigine, with between 2.7 and 6.6 per 1000 women receiving more than 1 prescription in 2016.

All regions did experience a reduction in the incidence of valproate prescribing during the whole study period. However, the results from fitting an interrupted time series model, indicated that in all regions there was a greater decline occurring post 2014 compared with pre 2014 for the prescription of valproate compared to the prescription of other AEDs. This decline was statistically significant in three of the regions.

\section{Strengths and Weaknesses}

Our study used electronic healthcare data and therefore exposure to AEDs was based on the issue/dispensing of a prescription. It was not possible to know whether the woman actually took the medicine and took it as and when instructed, although it is probably fair to assume that repeat prescribing of these products indicates actual use. Hence, in this study a woman was only defined as being exposed to an AED if she had at least 2 AED prescriptions over the study period. However this 
did result in excluding a large proportion of single AED prescriptions, as has been observed in other studies.[5]

None of the databases captured all AED prescriptions, but the proportions missed were thought to be small. For example, none captured prescriptions issued during in-patient hospital stays. In the UK, AED prescriptions issued by a specialist in secondary care were not captured, although the majority of AED prescribing, even if initiated by a specialist, would subsequently be undertaken by the GP. In France, AED prescriptions were not captured within the database if they were prescribed off label, which is an uncommon situation and in Italy a small number of AED products are not reimbursed by the Italian National Health Service. No information on the dose of AEDs prescribed was analysed.

A further weakness was that for three databases it was not possible to determine the indication for prescribing, partly related to the increasing number of indications for which AEDs are now prescribed $[1,2,26]$ and an increase in the extent of off-label prescribing[27]. A study in the UK, using electronic healthcare data, found that $62 \%$ of prescriptions issued for pregabalin between 2004 and 2009 did not have a diagnosis code corresponding to one of the approved indications[28]. The pattern of medications prescribed, particularly the increases in gabapentin and pregabalin, indicates that much of the increase in prescriptions was due to non-epilepsy indications, particularly pain treatments. This increase in AED prescriptions for non-epilepsy indications has been observed in Canada[2], Norway[29], Italy[6, 30], Denmark[5] and the US [31].

The results in this study are consistent with those in other earlier studies; the regional variations observed in the extent of AED prescribing and the AEDs most commonly prescribed have been reported elsewhere $[9,10,32]$, including a high prevalence of valproate prescribing in Italy between 2005 and 2011 [30]. The decline in the incidence of valproate prescribing in the UK is comparable with that reported by an Irish study between 2008 and 2013 [33] and a study of prescriptions to 1218 year olds in the UK [34].

The dramatic decline in the incidence of clonazepam prescribing observed in France is explained by changes in the rules on prescribing that came into effect between September 2011 and January 2012, following the observation of misuse and abuse of the product. Since September 2011, clonazepam can only be prescribed on a special prescription form that is usually specific to the prescribing of narcotics and controlled substances. Since January 2011 the initiation of clonazepam treatment has been restricted to neurologists and paediatricians. 
The relatively high levels of prescriptions for gabapentin and pregabalin, usually for neuropathic pain and the recent increases particularly in the UK and to some extent Tuscany have been reported earlier in Italy [3, 30] [6] the UK [9] and Norway[29]. Such increases have also occurred in nonEuropean countries such as Canada [2] and Australia [7]. These increases together with evidence that these AEDs have the potential for abuse [35], mean that the utilisation of these products requires future monitoring. In addition, more information is needed on the safety in pregnancy of these new AEDs, particularly for pregabalin. Two recent studies have produced conflicting results on the teratogenicity of pregabalin in the first trimester; the first was a multicentre study from the European Network of Teratology Information Services which reported an odds ratio $(O R)=3.0$ $(95 \% \mathrm{Cl}: 1.2-7.9)$ for pregabalin use in pregnancy and major congenital malformations in the fetus [36]. The second study using the US Medicaid Analytic Extract (MAX) reported a relative risk (RR) = 1.16 (95\% Cl: $0.81-1.67)$ for pregabalin use in pregnancy and major congenital malformations in the fetus after propensity score adjustment [37]. A recent review included nine studies on the safety of gabapentin use during pregnancy and concluded that there was no evidence of an increased risk of major congenital anomalies, but the studies were all small [38].

\section{Implications}

There is some evidence in the regions studied of a greater reduction in the prescribing of sodium valproate compared to other AEDs since 2014 compared with before 2014. However it is still of concern that in 2016 after pregabalin and gabapentin, valproate was the most commonly prescribed AED in all regions except for the UK (where lamotrigine was more common) with the prevalences of valproate prescriptions varying from 6.6 per 1000 in Tuscany down to 2.7 per 1000 in the UK. Much of the decrease in the incidence of prescribing valproate is occurring in older women, who may have already completed their families. In February 2018 the European Medicines Agency's PRAC recommended that sodium valproate must no longer be prescribed to women or girls of childbearing potential unless they are on the pregnancy prevention programme (PPP). The success of this could be monitored by studies similar to this one, but due to the differences observed across the regions studied here, in order to obtain a valid European measure of effect, more than four regions should be included.

This study has demonstrated that, in addition to epilepsy, AEDs are now being increasingly prescribed for other indications which means that data to evaluate the safety of AEDs should cover 
the full range of indications in addition to disease specific registries. It is important that all prescribing advice and warnings in addition to any interventions are made apparent to all potentially relevant prescribers, medical specialties, pharmacists and AED users and are not restricted to having the emphasis put on a particular indication.

The rapid increases observed in the prescribing of gabapentin and pregabalin in women of childbearing age and the lack of evidence of their safety during pregnancy means that further investigations into the use and safety in pregnancy of these medications should be performed.

\section{FUNDING}

This work was supported by the European Medicines Agency (EMA) grant number

$E M A / 2015 / 25 / P H$

\section{ACKNOWLEDGEMENTS}

The authors are very grateful for the input in the study design and analysis from the other members of the EUROmediSAFE consortium: Dr Vera Nelen, Dr Els Van de Mieroop, Dr Babak Khoshnood, Dr Pascale Tubert-Bitter, Dr Nathalie Lelong, Dr Anke Rissmann, Dr Jorieke van Kammen-Bergman , Dr Jen Bos, Professor Sue Jordan, Prof Helen Dolk and Prof Marlene Sinclair and from Dr Anita McGrogan.

\section{CONFLICTS OF INTEREST}

This document expresses the opinion of the authors of the paper, and may not be understood or quoted as being made on behalf or of reflecting the position of the European Medicines Agency or one of its committees or working parties.

\section{CONTRIBUTOR AND GUARANTOR INFORMATION}

$\mathrm{RC}$ and JKM contributed to the planning, conduct, analysis and reporting of the work and are responsible for the overall content. All other authors contributed to the conduct and analysis and provided input into the final paper. The corresponding author attests that all listed authors meet authorship criteria and that no others meeting the criteria have been omitted.

\section{DATA SHARING}

The authors are willing to consider reasonable requests for access to the aggregate data used in the analysis in this paper. 


\section{TRANSPARENCY STATEMENT}

Professor Joan Morris affirms that the manuscript is an honest, accurate, and transparent account of the study being reported; that no important aspects of the study have been omitted; and that any discrepancies from the study as originally planned (and, if relevant, registered) have been explained. 
Table 1: An overview of the databases contributing to the study

\begin{tabular}{|c|c|c|c|c|}
\hline Country/Region & $\begin{array}{r}\text { Italy - } \\
\text { Tuscany }\end{array}$ & $\begin{array}{r}\text { Italy - } \\
\text { Emilia Romagna }\end{array}$ & France & United Kingdom \\
\hline $\begin{array}{l}\text { Involves database } \\
\text { record linkage }\end{array}$ & Yes & Yes & Yes & No \\
\hline Population base & $3,700,000$ & $4,200,000$ & $\begin{array}{r}680,000(1 / 97 \text { of } \\
\text { French } \\
\text { population })\end{array}$ & $\begin{array}{r}5,000,000 \\
(\sim 8 \% \text { of the UK } \\
\text { population) } \\
\end{array}$ \\
\hline $\begin{array}{l}\text { Database for live \& } \\
\text { stillbirth pregnancy } \\
\text { identification }\end{array}$ & $\begin{array}{r}\text { Certificate of } \\
\text { Delivery } \\
\text { Assistance } \\
\text { (CeDAP) } \\
\text { Hospital } \\
\text { Discharges } \\
\text { Registry }\end{array}$ & $\begin{array}{r}\text { Certificate of } \\
\text { Delivery } \\
\text { Assistance } \\
(\text { CeDAP) }\end{array}$ & $\begin{array}{r}\text { Echantillon } \\
\text { Généraliste des } \\
\text { bénéficiaires } \\
(E G B)^{3}\end{array}$ & $\begin{array}{r}\text { Clinical Practice } \\
\text { Research } \\
\text { Datalink } \\
\text { (CPRD) }\end{array}$ \\
\hline $\begin{array}{l}\text { Database for } \\
\text { pregnancy loss } \\
\text { identification }\end{array}$ & $\begin{array}{r}\text { Discharges for } \\
\text { Induced } \\
\text { Terminations \& } \\
\text { Spontaneous } \\
\text { Abortions. } \\
\text { Hospital } \\
\text { Discharges } \\
\text { Registry }\end{array}$ & Not available & $\begin{array}{r}\text { EGB, French } \\
\text { Health } \\
\text { Insurance } \\
\text { System } \\
\text { and PMSI }\end{array}$ & CPRD \\
\hline $\begin{array}{l}\text { Database for medicine } \\
\text { use data }\end{array}$ & $\begin{array}{r}\text { Tuscany } \\
\text { Prescription } \\
\text { Database } \\
\text { (TPD) } \\
\end{array}$ & $\begin{array}{r}\text { Emilia-Romagna } \\
\text { Prescription } \\
\text { Database (ERPD) }\end{array}$ & $\begin{array}{r}\text { French Health } \\
\text { Insurance } \\
\text { System } \\
\text { Database } \\
\end{array}$ & CPRD \\
\hline $\begin{array}{l}\text { Source for medicine } \\
\text { use data }\end{array}$ & $\begin{array}{r}\text { Pharmacy } \\
\text { dispensing and } \\
\text { Healthcare } \\
\text { facilities } \\
\text { dispensing } \\
\text { (except } \\
\text { inpatient } \\
\text { exposure })^{2}\end{array}$ & $\begin{array}{r}\text { Pharmacy } \\
\text { dispensing and } \\
\text { Healthcare } \\
\text { facilities } \\
\text { dispensing } \\
\text { (except } \\
\text { inpatient } \\
\text { exposure) }{ }^{2}\end{array}$ & $\begin{array}{l}\text { Pharmacy } \\
\text { Dispensing }\end{array}$ & $\begin{array}{l}\text { GP practice } \\
\text { prescribing }^{1}\end{array}$ \\
\hline $\begin{array}{l}\text { Start of first data } \\
\text { collection }\end{array}$ & 2003 & 2003 & 2005 & 1987 \\
\hline $\begin{array}{l}\text { Capture outpatient } \\
\text { prescribing }\end{array}$ & Yes & Yes & Yes & Yes \\
\hline $\begin{array}{l}\text { Capture inpatient } \\
\text { prescribing }\end{array}$ & No & No & No & Some \\
\hline
\end{tabular}

${ }^{1}$ Including nurse prescribers working within the GP practice

${ }^{2}$ Including only products reimbursed by the Italian National Health Service and excluding those dispensed to outpatients in a hospital pharmacy

${ }^{3}$ EGB includes data from French Health insurance system \& Hospital Medical Information System databases (PMSI) 
Table 2: Numbers and prevalence of women aged 10 to 50 years with $>1$ prescription for an AED during 2016 according to region and ten most common AEDs

\begin{tabular}{|c|c|c|c|c|}
\hline & Tuscany & Emilia Romagna & France & UK \\
\hline $\begin{array}{l}\text { Number of women } \\
\text { in database in } 2016 \\
\text { [Mean age in years] }\end{array}$ & $\begin{array}{c}989,673 \\
{[33.0]}\end{array}$ & $\begin{array}{c}1,210,223 \\
{[33.2]}\end{array}$ & $\begin{array}{c}138,566 \\
{[31.4]}\end{array}$ & $\begin{array}{c}766,304 \\
{[31.2]}\end{array}$ \\
\hline $\begin{array}{l}\text { Number of women } \\
\text { with }>1 \text { AED } \\
\text { prescriptions in } \\
2016 \\
\text { [Mean age in years] }\end{array}$ & $\begin{array}{c}17,559 \\
{[37.7]} \\
\end{array}$ & $\begin{array}{c}14,733 \\
{[37.8]} \\
\end{array}$ & $\begin{array}{l}2,641 \\
{[38.3]}\end{array}$ & $\begin{array}{r}22,197 \\
{[37.7]} \\
\end{array}$ \\
\hline \multicolumn{5}{|c|}{ Prevalence per 1000 women $(95 \% \mathrm{Cl})$} \\
\hline Any AED & $\begin{array}{c}17.7 \\
(17.5-18.0)\end{array}$ & $\begin{array}{c}12.2 \\
(12.0-12.4) \\
\end{array}$ & $\begin{array}{c}19.1 \\
(18.3-19.8) \\
\end{array}$ & $\begin{array}{c}29.0 \\
(28.6-29.3) \\
\end{array}$ \\
\hline Gabapentin & $1.9(1.8-2.0)$ & $1.1(1.0-1.2)$ & $1.8(1.6-2.1)$ & $10.4(10.2-10.6)$ \\
\hline Pregabalin & $2.9(2.8-3.0)$ & $1.7(1.6-1.7)$ & $6.3(5.9-6.7)$ & $8.4(8.2-8.6)$ \\
\hline Valproate & $6.6(6.5-6.8)$ & $3.1(3.0-3.2)$ & $4.4(4.1-4.8)$ & $2.7(2.6-2.8)$ \\
\hline Topiramate & $2.2(2.1-2.3)$ & $1.6(1.5-1.6)$ & $1.7(1.5-1.9)$ & $2.5(2.4-2.6)$ \\
\hline Clonazepam & $1.5(1.4-1.6)$ & $1.7(1.7-1.8)$ & $0.8(0.7-1.0)$ & $0.8(0.7-0.8)$ \\
\hline Carbamazepine & $2.0(1.9-2.1)$ & $1.5(1.5-1.6)$ & $1.3(1.1-1.5)$ & $2.5(2.4-2.6)$ \\
\hline Lamotrigine & $1.9(1.8-2.0)$ & $1.9(1.8-1.9)$ & $3.1(2.9-3.4)$ & $4.3(4.1-4.4)$ \\
\hline Levetiracetam & $1.2(1.2-1.3)$ & $1.3(1.3-1.4)$ & $1.7(1.5-1.9)$ & $2.2(2.1-2.3)$ \\
\hline Clobazam & - & $0.1(0.1-0.1)$ & $1.6(1.4-1.8)$ & $0.7(0.6-0.7)$ \\
\hline Oxcarbazepine & $0.9(0.8-0.9)$ & $0.6(0.5-0.6)$ & $0.5(0.3-0.6)$ & $0.1(0.1-0.1)$ \\
\hline
\end{tabular}

Table 3: Odds ratio of prescribing sodium valproate compared to another AED (excluding clonazepam, gabapentin and pregabalin) per year for each region : comparing 2007-2013 with 2014-2016

\begin{tabular}{|l|c|c|c|c|}
\hline & \multicolumn{2}{|c|}{$\begin{array}{c}\text { Odds ratio of prescribing sodium valproate } \\
\text { compared to another AED per year }\end{array}$} & $\begin{array}{c}\text { Ratio of OR } \\
2014-2016 \text { vs } \\
2007-2013\end{array}$ & $\begin{array}{c}\text { P values for } \\
\text { comparison } \\
\text { of odds } \\
\text { ratios }\end{array}$ \\
\hline $\begin{array}{l}\text { Emilia } \\
\text { Romagna }\end{array}$ & $1.01(1.00-1.03)$ & $0.84(0.78-0.91)$ & $0.83(0.76-0.90)$ & $<0.001$ \\
\hline France & $0.94(0.90-0.98)$ & $0.72(0.56-0.91)$ & $0.77(0.60-0.98)$ & 0.033 \\
\hline Tuscany & $1.05(1.04-1.06)$ & $0.85(0.80-0.91)$ & $0.81(0.76-0.86)$ & $<0.001$ \\
\hline UK & $0.87(0.85-0.89)$ & $0.80(0.69-0.92)$ & $0.92(0.80-1.06)$ & 0.262 \\
\hline
\end{tabular}


Table 4 : Percentage of women with > 1 prescription for an AED for the first time from 2007-2016 according to indication in France (Totals may be above $\mathbf{1 0 0 \%}$ as some women are prescribed medications for multiple reasons).

\begin{tabular}{|c|c|c|c|c|c|c|c|}
\hline & \multicolumn{2}{|c|}{ Percentage of women (\%) } \\
\hline $\begin{array}{c}\text { Number } \\
\text { of } \\
\text { women }\end{array}$ & Epilepsy & Bipolar & Anxiety & $\begin{array}{c}\text { Neuropathic } \\
\text { pain }\end{array}$ & $\begin{array}{c}\text { Migraine } \\
\text { Other / } \\
\text { Unknown }\end{array}$ \\
\hline Any AED & $\mathbf{7 3 8 2}$ & $\mathbf{3 1}$ & $\mathbf{1 6}$ & $\mathbf{4}$ & $\mathbf{4 0}$ & $\mathbf{1}$ & $\mathbf{1 1}$ \\
\hline Gabapentin & 418 & 23 & 2 & 2 & 73 & 0 & 0 \\
\hline Pregabalin & 2584 & 15 & 2 & 4 & 79 & 0 & 0 \\
\hline Valproate & 1059 & 29 & 81 & 0 & 0 & 0 & 0 \\
\hline Topiramate & 388 & 80 & 3 & 1 & 0 & 16 & 0 \\
\hline Clonazepam & 1874 & 20 & 6 & 0 & 37 & 0 & 43 \\
\hline Carbamazepine & 214 & 76 & 20 & 1 & 3 & 0 & 0 \\
\hline Lamotrigine & 243 & 67 & 34 & 0 & 0 & 0 & 0 \\
\hline Levetiracetam & 189 & 100 & 0 & 0 & 0 & 0 & 0 \\
\hline Clobazam & 579 & 67 & 6 & 25 & 0 & 0 & 3 \\
\hline Oxcarbazepine & 41 & 100 & 7 & 0 & 0 & 0 & 0 \\
\hline
\end{tabular}




\section{Figure legends:}

Figure 1: Trends in the incidence of first prescriptions in the four regions from 2007 to 2016 (a) Incidence of any AED and (b) incidence of any AED excluding clonazepam, gabapentin and pregabalin.

Figure 2: Incidence of prescribing sodium valproate according to year of first prescription and region (a) per 10,000 women and (b) expressed as a proportion of all AEDs (excluding clonazepam, gabapentin and pregabalin).

Figure 3: Incidence of sodium valproate prescriptions per 10,000 person years according to age at first prescription and year of prescription in the four regions

Figure 4: Incidence of prescriptions for valproate according to year at first prescription, indication and age in France 
REFERENCES

1. Johannessen Landmark C, Larsson PG, Rytter E, Johannessen SI. Antiepileptic drugs in epilepsy and other disorders-A population-based study of prescriptions. Epilepsy research. 2009;87(1):31-9. doi: https://doi.org/10.1016/i.eplepsyres.2009.07.005.

2. Leong C, Mamdani MM, Gomes T, Juurlink DN, Macdonald EM, Yogendran M. Antiepileptic use for epilepsy and nonepilepsy disorders. A population-based study (1998-2013). 2016;86(10):939-46. doi: 10.1212/wnl.0000000000002446.

3. Savica R, Beghi E, Mazzaglia G, Innocenti F, Brignoli O, Cricelli C, et al. Prescribing patterns of antiepileptic drugs in Italy: a nationwide population-based study in the years 2000-2005. European Journal of Neurology. 2007;14(12):1317-21. doi: doi:10.1111/j.1468-1331.2007.01970.x.

4. Hayes J, Prah P, Nazareth I, King M, Walters K, Petersen I, et al. Prescribing Trends in Bipolar Disorder: Cohort Study in the United Kingdom THIN Primary Care Database 1995-2009. PLOS ONE. 2011;6(12):e28725. doi: 10.1371/journal.pone.0028725.

5. Tsiropoulos I, Gichangi A, Andersen M, Bjerrum L, Gaist D, Hallas J. Trends in utilization of antiepileptic drugs in Denmark. Acta Neurologica Scandinavica. 2006;113(6):405-11. doi: doi:10.1111/j.1600-0404.2006.00639.x.

6. Alacqua M, Trifiro G, Spina E, Moretti S, Tari DU, Bramanti P, et al. Newer and older antiepileptic drug use in Southern Italy: a population-based study during the years 2003-2005. Epilepsy research. 2009;85(1):107-13. Epub 2009/04/07. doi: 10.1016/j.eplepsyres.2009.03.002. PubMed PMID: 19345564.

7. Hollingworth SA, Eadie MJ. Antiepileptic drugs in Australia: 2002-2007.

Pharmacoepidemiology and drug safety. 2010;19(1):82-9. Epub 2009/10/06. doi: 10.1002/pds.1871. PubMed PMID: 19802824.

8. Landmark CJ, Fossmark H, Larsson PG, Rytter E, Johannessen SI. Prescription patterns of antiepileptic drugs in patients with epilepsy in a nation-wide population. Epilepsy research. 2011;95(1-2):51-9. Epub 2011/03/26. doi: 10.1016/j.eplepsyres.2011.02.012. PubMed PMID: 21435840.

9. de Groot $\mathrm{MCH}$, Schuerch M, Vries F, Hesse U, Oliva B, Gil M, et al. Antiepileptic drug use in seven electronic health record databases in Europe: A methodologic comparison. Epilepsia. 2014;55(5):666-73. doi: doi:10.1111/epi.12557.

10. Charlton R, Garne E, Wang H, Klungsoyr K, Jordan S, Neville A, et al. Antiepileptic drug prescribing before, during and after pregnancy: a study in seven European regions.

Pharmacoepidemiology and drug safety. 2015;24(11):1144-54. Epub 2015/08/15. doi: 10.1002/pds.3847. PubMed PMID: 26272314.

11. Vajda FJ, Horgan D, Hollingworth S, Graham J, Hitchcock AA, Roten A, et al. The prescribing of antiepileptic drugs for pregnant Australian women. Aust N Z J Obstet Gynaecol. 2012;52(1):49-53. Epub 2011/09/14. doi: 10.1111/j.1479-828X.2011.01359.x. PubMed PMID: 21910695.

12. Man S-L, Petersen I, Thompson M, Nazareth I. Antiepileptic Drugs during Pregnancy in Primary Care: A UK Population Based Study. PLOS ONE. 2012;7(12):e52339. doi:

10.1371/journal.pone.0052339.

13. Bobo WV, Davis RL, Toh S, Li DK, Andrade SE, Cheetham TC, et al. Trends in the use of antiepileptic drugs among pregnant women in the US, 2001-2007: a medication exposure in pregnancy risk evaluation program study. Paediatr Perinat Epidemiol. 2012;26(6):578-88. Epub 2012/10/16. doi: 10.1111/ppe.12004. PubMed PMID: 23061694; PubMed Central PMCID: PMCPMC3481178. 
14. Meador K, Reynolds MW, Crean S, Fahrbach K, Probst C. Pregnancy outcomes in women with epilepsy: a systematic review and meta-analysis of published pregnancy registries and cohorts. Epilepsy research. 2008;81(1):1-13. Epub 2008/06/21. doi: 10.1016/j.eplepsyres.2008.04.022. PubMed PMID: 18565732; PubMed Central PMCID: PMCPMC2660205.

15. Morrow J, Russell A, Guthrie E, Parsons L, Robertson I, Waddell R, et al. Malformation risks of antiepileptic drugs in pregnancy: a prospective study from the UK Epilepsy and Pregnancy Register. Journal of neurology, neurosurgery, and psychiatry. 2006;77(2):193-8. Epub 2005/09/15. doi: 10.1136/jnnp.2005.074203. PubMed PMID: 16157661; PubMed Central PMCID: PMCPMC2077578.

16. Thomas SV, Jose M, Divakaran S, Sankara Sarma P. Malformation risk of antiepileptic drug exposure during pregnancy in women with epilepsy: Results from a pregnancy registry in South India. Epilepsia. 2017;58(2):274-81. Epub 2017/01/14. doi: 10.1111/epi.13632. PubMed PMID: 28084641.

17. Weston J, Bromley R, Jackson CF, Adab N, Clayton-Smith J, Greenhalgh J, et al. Monotherapy treatment of epilepsy in pregnancy: congenital malformation outcomes in the child. The Cochrane database of systematic reviews. 2016;11:Cd010224. Epub 2016/11/08. doi:

10.1002/14651858.CD010224.pub2. PubMed PMID: 27819746.

18. Bromley R, Weston J, Adab N, Greenhalgh J, Sanniti A, McKay AJ, et al. Treatment for epilepsy in pregnancy: neurodevelopmental outcomes in the child. The Cochrane database of systematic reviews. 2014;(10):Cd010236. Epub 2014/10/31. doi:

10.1002/14651858.CD010236.pub2. PubMed PMID: 25354543.

19. Bromley RL, Mawer G, Clayton-Smith J, Baker GA. Autism spectrum disorders following in utero exposure to antiepileptic drugs. Neurology. 2008;71(23):1923-4. Epub 2008/12/03. doi: 10.1212/01.wnl.0000339399.64213.1a. PubMed PMID: 19047565.

20. Cummings C, Stewart M, Stevenson M, Morrow J, Nelson J. Neurodevelopment of children exposed in utero to lamotrigine, sodium valproate and carbamazepine. Archives of Disease in Childhood. 2011;96(7):643-7. PubMed PMID: 10.1136/adc.2009.176990.

21. Meador KJ, Penovich P, Baker GA, Pennell PB, Bromfield E, Pack A, et al. Antiepileptic drug use in women of childbearing age. Epilepsy Behav. 2009;15(3):339-43. Epub 2009/05/05. doi: 10.1016/j.yebeh.2009.04.026. PubMed PMID: 19410654; PubMed Central PMCID: PMCPMC2741411.

22. Thomas SV, Sukumaran S, Lukose N, George A, Sarma PS. Intellectual and language functions in children of mothers with epilepsy. Epilepsia. 2007;48(12):2234-40. Epub 2007/10/19. doi: 10.1111/j.1528-1167.2007.01376.x. PubMed PMID: 17941847.

23. Meador KJ, Baker GA, Browning N, Cohen MJ, Bromley RL, Clayton-Smith J, et al. Fetal antiepileptic drug exposure and cognitive outcomes at age 6 years (NEAD study): a prospective observational study. The Lancet Neurology. 2013;12(3):244-52. Epub 2013/01/29. doi: 10.1016/s1474-4422(12)70323-x. PubMed PMID: 23352199; PubMed Central PMCID: PMCPMC3684942.

24. Charlton RA, Neville AJ, Jordan S, Pierini A, Damase-Michel C, Klungsoyr K, et al. Healthcare databases in Europe for studying medicine use and safety during pregnancy. Pharmacoepidemiology and drug safety. 2014;23(6):586-94. Epub 2014/03/26. doi: 10.1002/pds.3613. PubMed PMID: 24664855.

25. Naldi I, Piccinni C, Mostacci B, Renzini J, Accetta G, Bisulli F, et al. Prescription patterns of antiepileptic drugs in young women: development of a tool to distinguish between epilepsy and psychiatric disorders. Pharmacoepidemiology and drug safety. 2016;25(7):763-9. Epub 2016/02/19. doi: 10.1002/pds.3984. PubMed PMID: 26887800.

26. Grunze HCR. The effectiveness of anticonvulsants in psychiatric disorders. Dialogues in Clinical Neuroscience. 2008;10(1):77-89. PubMed PMID: PMC3181858.

27. Atturu H, Odelola A. Valproate Prescribing in Women of Childbearing Age: An Audit of Clinical Practice. Advances in Psychiatry. 2015;2015:6. doi: 10.1155/2015/520784. 
28. Asomaning K, Abramsky S, Liu Q, Zhou X, Sobel RE, Watt S. Pregabalin prescriptions in the United Kingdom: a drug utilisation study of The Health Improvement Network (THIN) primary care database. International journal of clinical practice. 2016;70(5):380-8. Epub 2016/03/31. doi: 10.1111/ijcp.12791. PubMed PMID: 27028939.

29. Baftiu A, Johannessen Landmark C, Rusten IR, Feet SA, Johannessen SI, Larsson PG. Changes in utilisation of antiepileptic drugs in epilepsy and non-epilepsy disorders-a

pharmacoepidemiological study and clinical implications. European Journal of Clinical Pharmacology. 2016;72(10):1245-54. doi: 10.1007/s00228-016-2092-3.

30. Italiano D, Capuano A, Alibrandi A, Ferrara R, Cannata A, Trifirò G, et al. Indications of newer and older anti-epileptic drug use: findings from a southern Italian general practice setting from 2005-2011. British Journal of Clinical Pharmacology. 2015;79(6):1010-9. doi: 10.1111/bcp.12577. PubMed PMID: PMC4456133.

31. Adedinsewo DA, Thurman DJ, Luo YH, Williamson RS, Odewole OA, Oakley GP, Jr. Valproate prescriptions for nonepilepsy disorders in reproductive-age women. Birth defects research Part A, Clinical and molecular teratology. 2013;97(6):403-8. Epub 2013/06/05. doi: 10.1002/bdra.23147. PubMed PMID: 23733498.

32. EURAP. Utilization of antiepileptic drugs during pregnancy: comparative patterns in 38 countries based on data from the EURAP registry. Epilepsia. 2009;50(10):2305-9. Epub 2009/05/21. doi: 10.1111/j.1528-1167.2009.02093.x. PubMed PMID: 19453723.

33. Murphy S, Bennett K, Doherty CP. Prescribing trends for sodium valproate in Ireland. Seizure. 2016;36:44-8. Epub 2016/02/21. doi: 10.1016/j.seizure.2016.01.019. PubMed PMID: 26896815.

34. Ackers R, Besag FM, Wade A, Murray ML, Wong IC. Changing trends in antiepileptic drug prescribing in girls of child-bearing potential. Arch Dis Child. 2009;94(6):443-7. Epub 2009/03/25. doi: 10.1136/adc.2008.144386. PubMed PMID: 19307197.

35. Caster O, Edwards IR, Noren GN, Lindquist M. Earlier discovery of pregabalin's dependence potential might have been possible. Eur J Clin Pharmacol. 2011;67(3):319-20. Epub 2010/10/26. doi: 10.1007/s00228-010-0920-4. PubMed PMID: 20972557.

36. Winterfeld U, Merlob P, Baud D, Rousson V, Panchaud A, Rothuizen LE, et al. Pregnancy outcome following maternal exposure to pregabalin may call for concern. Neurology. 2016;86(24):2251-7. Epub 2016/05/20. doi: 10.1212/wnl.0000000000002767. PubMed PMID: 27194385.

37. Patorno E, Bateman BT, Huybrechts KF, MacDonald SC, Cohen JM, Desai RJ, et al. Pregabalin use early in pregnancy and the risk of major congenital malformations. Neurology.

2017;88(21):2020-5. Epub 2017/04/28. doi: 10.1212/wnl.0000000000003959. PubMed PMID: 28446648; PubMed Central PMCID: PMCPMC5440246.

38. de Jong J, Garne E, de Jong-van den Berg LTW, Wang H. The Risk of Specific Congenital Anomalies in Relation to Newer Antiepileptic Drugs: A Literature Review. Drugs - Real World Outcomes. 2016;3(2):131-43. doi: 10.1007/s40801-016-0078-1. PubMed PMID: PMC4914544. 